\title{
Expression and clinical significance of the DNA repair enzyme MYH in esophageal squamous cell carcinoma
}

\author{
KAI SHEN ${ }^{*}$, YONG JI* , GUO-QIANG CHEN, BIN HUANG, XIAN ZHANG, \\ SONG WU, GUI-PING YU and XIAO-CHEN WANG
}

Department of Cardiothoracic Surgery, Jangyin People's Hospital, Dongnan University, Jiangyin, Jiangsu 214400, P.R. China

Received June 3, 2011; Accepted July 18, 2011

DOI: $10.3892 /$ etm.2011.320

\begin{abstract}
MYH is an important enzyme in combating DNA oxidative stress in the occurrence and development of various types of tumors. To investigate the correlation between expression of the DNA repair enzyme MYH in esophageal squamous cell carcinoma and 8-oxoguanine (8-oxoG) oxidative damage, as well as the clinical significance of altered MYH expression, tissues from 175 esophageal carcinoma cases were investigated in the present study. MYH expression and 8-oxoG oxidative damage in squamous cell carcinoma and adjacent normal tissue were assessed by immunohistochemistry and Western blotting. In $82.9 \%$ (145/175) of the cases, MYH protein expression in esophageal squamous cell carcinoma was lower than that of adjacent normal tissue ( $\mathrm{t}=4.24, \mathrm{P}<0.001)$. Additionally, 8-oxoG staining was higher in the tumors than in the normal tissue. Lower expression of MYH in esophageal squamous cell carcinoma was associated with depth of invasion, venous invasion, TNM stage and lymph node metastasis $(\mathrm{P}<0.05)$. In conclusion, a lower MYH expression level in esophageal cell carcinoma tissue was inversely associated with more severe 8-oxoG oxidative damage, suggesting that changes in MYH activity correspond to increased DNA damage in tumor cells. The use of MYH expression as a postoperative index for esophageal squamous cell carcinoma may guide the formulation of individualized chemotherapy for patients after surgery.

\section{Introduction}

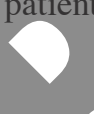

Esophageal carcinoma is a common type of cancer worldwide and is particularly prevalent in China. Because of its prevalence, recent genetic and genomic studies have focused on
\end{abstract}

Correspondence to: Dr Kai Shen, Department of Cardiothoracic Surgery, Jiangyin People's Hospital, Dongnan University, 163 Shoushan, Jiangyin, Jiangsu 214400, P.R. China

E-mail: shenkai0625@126.com

${ }^{*}$ Contributed equally

Key words: esophageal squamous cell carcinoma, MYH, 8-oxoguanine understanding esophageal squamous cell carcinoma (ESCC) in Chinese populations $(1,2)$. In this type of cancer, oxidative damage occurs continuously in DNA as a result of normal metabolism as well as other internal and external factors. 8-oxoguanine (8-oxoG), which is generated from oxidative attack on guanine, is the most common form of oxidative DNA damage and displays a strong mutagenicity $(3,4)$. One important enzyme that combats oxidative damage is $\mathrm{MYH}$, a homolog of the transglucokinase Mut Y, which functions during DNA base excision repair and plays a significant role in the occurrence and development of various tumor types (5-10). Since early detection of ESCC is difficult, with diffusion and metastasis typically occurring before diagnosis, we sought to determine whether MYH serves as a molecular marker for this disease. We investigated expression changes in MYH in ESCC. Furthermore, we determined the correlation of these expression changes with 8 -oxoG oxidative damage and clinicopathological characteristics of ESCC. Our findings may provide a molecular foundation for the formulation of chemotherapy schemes following surgery for squamous cell carcinoma.

\section{Materials and methods}

Materials. For this study, 175 tissue samples and relevant clinical data were obtained from ESCC patients, including 89 paraffin-embedded samples of esophageal carcinoma and corresponding adjacent normal tissue, and 86 fresh surgical specimens excised during radical surgery for esophageal carcinoma between June 2008 and June 2010 in our hospital.

Immunohistochemistry. Fresh specimens were fixed using $4 \%$ paraformaldehyde, coated with paraffin wax, serially sectioned at $4 \mu \mathrm{m}$ and placed on slides. Following antigen retrieval by high heat, sections were stained according to the manufacturer's instructions for the streptavidin biotin complex (SABC) kit (Boster Co., Ltd., China). An MYH rabbit antihuman polyclonal antibody (Santa Cruz Biotechnology, Inc.) was applied at a working concentration of 1:400; the negative control replaced the primary antibody with PBS and the positive control included known-positive normal esophageal tissue slices. The 8-oxoG sheep anti-human polyclonal antibody (Abcam), required to test for oxidative damage, was applied at a working concentration of 1:200. 


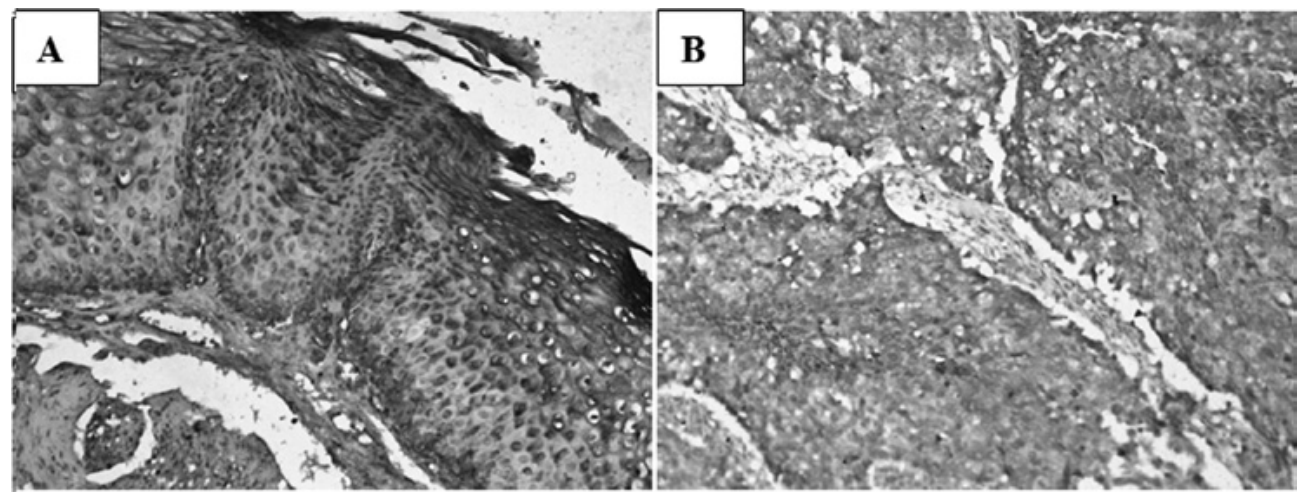

Figure 1. MYH protein expression in esophageal squamous cell carcinoma and adjacent normal tissue as assessed by immunohistochemistry. (A) Adjacent normal tissue; (B) squamous cell carcinoma.

Protein extraction and Western blotting. A portion of each fresh tissue specimen was digested to obtain protein. Following centrifugation, supernatants were used for determination of the protein concentration using colorimetry. SDS-PAGE electrophoresis was used on a total protein volume of $10-\mu \mathrm{g} /$ pore, with samples electrically transferred onto a PVDF membrane. MYH rabbit anti-human polyclonal antibody (1:200) and $\beta$-actin rabbit polyclonal antibody (1:200; Nanjing Burke Corporation) were used as previously described (5). Results were analyzed by ScnImage software (Scion Corporation, Frederick, MD, USA).

Scoring of MYH immunohistochemical staining. As prev ously described (3), immunohistochemical staining was scored based on the positive cell percentage without tumor border and necrotic regions. Thus, a positive cell percentage $<20 \%$ was scored as 0 ; a positive cell percentage $20-60 \%$ was scored as 1 ; a positive cell percentage $>60-80 \%$ was scored as 2 ; and a positive cell percentage $>80 \%$ was scored as 3 . At the same time, the depth of the color of the cell staining was also scored. No color was marked as 1 , weak color was marked as 1 , medium color was marked as 2 and strong color was marked as 3 . The above two scores were multiplied and treated as the final scores for MYH immunohistochemical staining.

Cell death was scored as follows: absence of death was marked as 0 , minimal death was marked as 1 , moderate death was marked as 2 and severe death was marked as 3 .

Scoring of 8-oxoG immunohistochemical staining. As previously described (3), 8-oxoG-positive cells were counted among 100 esophageal squamous epithelia (in carcinoma and adjacent normal tissue).

Statistical analysis. Statistical tests were performed with SPSS 13.0. Data were compared by the $\chi^{2}$ test, t-test and correlation analysis. Related influence factors of low MYH expression in ESCC were analyzed by logistic regression. The dependent variable was 'low MYH expression' (yes=1 and no=0); the independent variables were 'venous invasion' (yes $=1$ and no=0), 'TNM stage' ( $\mathrm{I}$ and II=1, III and IV=2), 'invasive depth of esophageal carcinoma' $(\mathrm{T} 1+\mathrm{T} 2=1$ and $\mathrm{T} 3+\mathrm{T} 4=2$ ) and 'lymph node metastasis' (yes=1 and no=0). $\alpha$ level was equal to 0.05 , with P-value $<0.05$ indicating a statistically significant difference.

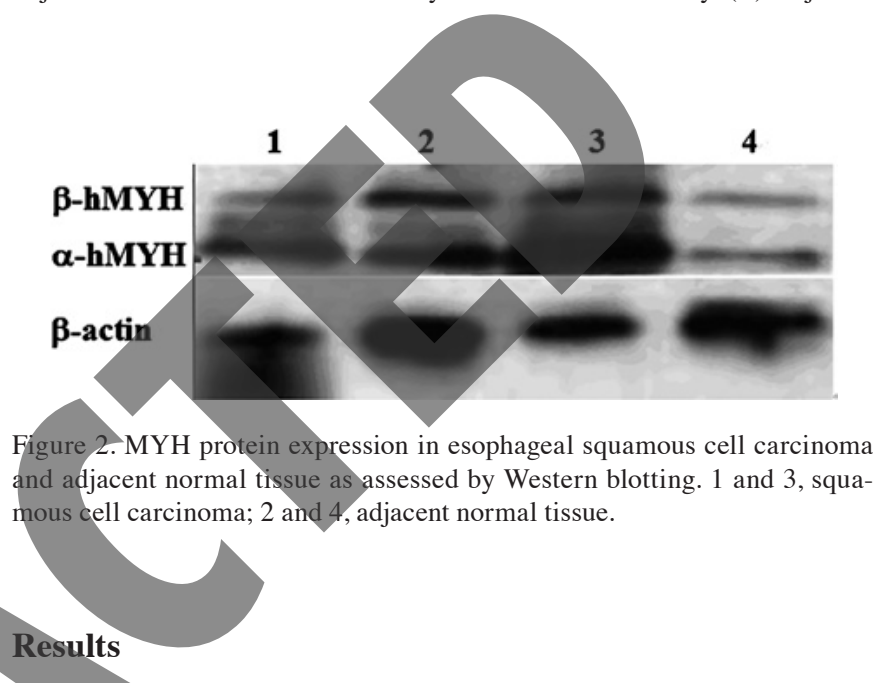

MYH expression in esophageal squamous cell carcinoma and adjacent normal tissue. In both the normal esophageal tissue and ESCC, MYH protein was detected by immunohistochemistry as fine sepia-toned granules in the nuclei (Fig. 1). Among 175 cases, $145(82.9 \%)$ samples displayed lower MYH protein expression in ESCC than in the adjacent normal tissue. Seven cases had indistinguishable MYH protein expression between ESCC and the adjacent normal tissue. Using the described scoring methods, MYH staining in the adjacent normal tissue and ESCC was graded as $2.35 \pm 1.68$ and $1.47 \pm 0.96$, respectively, demonstrating the higher percentage of positive cells in adjacent normal tissue than in ESCC. This difference was statistically significant $(\mathrm{t}=4.24, \mathrm{P}<0.001)$.

Analysis of MYH expression by Western blotting in 86 fresh specimens (Fig. 2). In 72 cases (83.1\%), MYH protein expression was lower in ESCC than in the adjacent normal tissue; 10 cases displayed higher MYH protein expression in ESCC than in the adjacent normal tissue, and 4 cases had no obvious difference in expression. Thus, similar results were obtained by the two different methods of detecting MYH expression.

8-oxoG oxidative damage in esophageal squamous cell carcinoma and adjacent normal tissue. In 175 cases, 8-oxoG oxidative damage was detected by immunohistochemistry in ESCC and adjacent normal tissue. Positive cells were tan in color, although staining was restricted mainly to the nuclei. 8-oxoG oxidative damage was more severe in ESCC that in the adjacent normal tissue in 119 cases $(68.0 \%)$, the remaining 56 cases had low expression levels of 8-oxoG oxidative damage. 
Table I. Correlation between MYH expression and 8-oxoG oxidative damage in esophageal squamous cell carcinoma.

\begin{tabular}{lccc}
\hline & High MYH expression & Low MYH expression & Total \\
\hline High 8-oxoG expression & 2 & 54 & 56 \\
Low 8-oxoG expression & 28 & 91 & 119 \\
Total & 30 & 145 & 175 \\
\hline
\end{tabular}

Table II. Low MYH expression in esophageal squamous cell carcinoma and clinicopathological characteristics of patients analyzed by logistic regression.

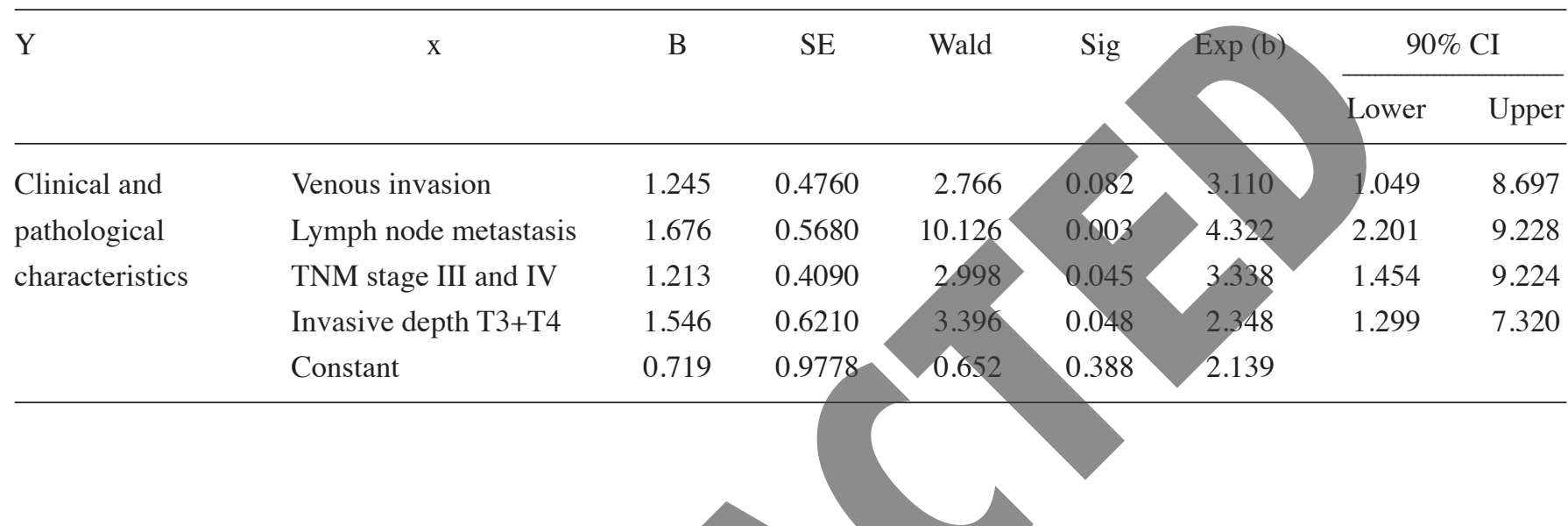

Correlation between MYH expression and 8-oxoG oxidative and homolog of Mut $\mathrm{Y}$ that plays a significant role in the damage. Compared to adjacent normal tissue, the low expres- excision repair of long-fragment bases. MYH interacts with sion rate of MYH protein in squamous cell careinoma was apurinic/apyrimidinic endonuclease (APE) and proliferating$82.9 \%$ (145/175), while it was 68.0\% (119/175) for squamous cell nuclear antigen (PCNA); furthermore, this enzyme cell carcinoma in contrast to high 8-oxoG oxidative damage. excises adenine among G:A, G:A and C:A mismatched by Using correlation analysis, a negative eorrelation was found 8-0xo, and then resects 8-oxo for repair by 8-oxoguanine between the two groups $(\mathrm{r}=-0.247)$; thus, lower MYH protein DNA glycosylase (OGG1) $(13,14)$. Mutations in MYH are expression in ESCC corresponded to a higher 8-OxoG oxida- involved in the initiation and progression of pulmonary, tive damage level (Table I).

Correlation between low MYH expression in esophageal squamous cell carcinoma, and clinical and pathological characteristics of patients. Univariate analysis $\left(\chi^{2}\right.$ test) was carried out for low MYH expression and the clinical and pathological characteristics of patients. Differences were not detected between low MYH expression and gender, age or pathological differentiation. However, differences between low MYH expression and venous invasion, lymph node metastasis and invasive depth were statistically significant $(\mathrm{P}<0.05)$. Significant variables identified by univariate analysis were analyzed by logistic regression. A higher ratio was detected between venous invasion, lymph node metastasis, invasion of T3+T4 and TNM stages III and IV, and low MYH expression (Table II).

\section{Discussion}

8-oxoG is the main product of DNA oxidative damage and a precursor of mutagenic substances. During DNA replication, 8-oxoG pairs with adenine, resulting in a transversion from $\mathrm{G}: \mathrm{C}$ to T:A and base mutation $(11,12)$. This type of DNA damage is typically repaired by base excision. One important enzyme required for this repair is MYH, a transglucokinase ovarian and gastrointestinal cancers, lymphoma and various other tumor types (5-10).

We aimed to correlate the expression of MYH with the presence of oxidative damage in esophageal tumors. Our results revealed that MHY protein is expressed at lower levels in ESCC than in adjacent normal tissues. This finding is consistent with a study by Bonde et al (15), in which MYH expression was lower in ESCC than in normal esophageal mouse tissues. Additionally, we detected 8-oxoG at a higher level in ESCC than in normal tissue, and correlation analysis indicated that lower MYH expression in ESCC corresponded to higher levels of 8-oxoG oxidative damage. This observation confirms that low MYH protein expression in ESCC is related to the development of ESCC. Furthermore, reduced MYH in ESCC is related to increased 8-oxoG oxidative damage, venous invasion, invasive depth, TNM stage and lymph node metastasis. These results suggest that abnormal expression of MYH may promote malignancy in esophageal tissue cells.

We hypothesize, based on our findings, that the prognosis of esophageal carcinoma correlates with MYH expression; thus, MYH plays a role in the occurrence and development of ESCC and may be used as a molecular marker. We suggest that MYH may be used as an index for chemotherapy and surgical outcomes, and may help guide the formulation of individualized treatment schemes following surgery. 


\section{References}

1. Wang N, Dong XJ, Zhou RM, Guo W, Zhang XJ and Li Y: An investigation on the polymorphisms of two DNA repair genes and susceptibility to ESCC and GCA of high-incidence region in northern China. Mol Biol Rep 36: 357-364, 2009.

2. Su H, Hu N, Yang HH, Wang C, Takikita M, Wang QH, Giffen C, Clifford R, Hewitt SM, Shou JZ, Goldstein AM, Lee MP and Taylor PR: Global gene expression profiling and validation in esophageal squamous cell carcinoma (ESCC) and its association with clinical phenotypes. Clin Canc Res 17: 2955-2966, 2011.

3. Bonde P, Gao D, Chen L, Duncan M, Miyashita T, Montgomery E, Harmon JW and Wei C: Selective decrease in the DNA base excision repair pathway in squamous cell cancer of the esophagus. Thorac Cardiovasc Surg 133: 74-81, 2007

4. Hagiwara A, Kitajima Y, Sato S and Miyazaki K: Allelic loss of the DNA repair gene OGG1 against oxidative damage in esophageal squamous cell carcinoma. Oncol Rep 13: 1009-1016, 2005.

5. Boparai KS, Dekker E, van Eeden S, Polak MM, Bartelsman JF, Mathus-Vliegen EM, Keller JJ and van Noesel CJ: Hyperplastic polyps and sessile serrated adenomas as a phenotypic expression of MYH-associated polyposis. Gastroenterol 135: 2014-2018, 2008.

6. Balaguer F, Castellví-Bel S, Castells A, et al: Identification of MYH mutation carriers in colorectal cancer: a multicenter, casecontrol, population-based study. Clin Gastroenterol Hepatol 5: 379-387, 2007.

7. De Ferro SM, Suspiro A, Fidalgo P, Lage P, Rodrigues P, Fragoso S, Vitoriano I, Baltazar C, Albuquerque C, Bettencourt A and Leitão CN: Aggressive phenotype of MYH-associated polyposis with jejunal cancer and intra-abdominal desmoid tumor: report of a case. Dis Colon Rectum 52: 742-745, 2009.
8. Shin EJ, Chappell E, Pethe V, Hersey K, van der Kwast T, Fleshner $\mathrm{N}$ and Bapat $\mathrm{B}$ : MYH mutations are rare in prostate cancer. J Cancer Res Clin Oncol 133: 373-378, 2007.

9. Baudhuin LM, Roberts LR, Enders FT, Swanson RL, Mettler TA, Aderca I, Stadheim LM and Highsmith WE: MYH Y165C and G382D mutations in hepatocellular carcinoma and cholangiocarcinoma patients. J Cancer Res Clin Oncol 132: 159-162, 2006.

10. Russo MT, De Luca G,Degan P, Parlanti E, Dogliotti E, Barnes DE, Lindahl T, Yang $\mathrm{H}$, Miller JH and Bignami M: Accumulation of the oxidative base lesion 8-hydroxyguanine in DNA of tumor-prone mice defective in both the Myh and Ogg1 DNA glycosylases. Cancer Res 64: 4411-4414, 2004.

11. Jasson K, Blomberg A, Sunnerhagen P and Alm Rosenblad M: Evolutionary loss of 8-oxo-G repair components among eukaryotes. Genome Integr 1: 12-14, 2010.

12. Dalhus B, Forsbring M, Helle IH, Vik ES and Forstrøãs M: Separation-of-function mutants unravel the dual-reaction mode of huma 8-oxoguanine DNA glycosylase. Structure 19: 117-127, 2011.

13. Lu AL, Bai H, Shi G and Chang DY: MutY and MutY homologs $(\mathrm{MYH})$ in genome maintenance. Front Bìosci 11: 3062-3080, 2006.

14. Yang H, Clendenin WM, Wong D, Demple B, Slupska MM, Chiang $\mathrm{JH}$ and Miller JH: Enhanced activity of adenine-DNA glycosylase (Myh) by apurinic apyrimidinic endonuclease (Ape1) in mammalian base exeision repair of an A/GO mismatch. Nucleic Acids Res 29: 743-752, 2001.

15. Bonde P, Gao D, Chen L, Miyashita T, Montgomery E, Harmon JW and Wei C: Duodenal reflux leads to down regulation of DNA mismatch repair pathway in an animal model of esophageal cancer. Ann Thorac Surg 83: 433-440, 2007. 